\title{
Increased urinary nitrate excretion in rats with adjuvant arthritis
}

\author{
Dirk O Stichtenoth, Frank-M Gutzki, Dimitrios Tsikas, Norma Selve, \\ Stefanie M Bode-Böger, Rainer H Böger, Jürgen C Frölich
}

\begin{abstract}
Objectives-In rats with adjuvant arthritis measurements were taken of the urinary excretion of nitrate, reflecting endogenous nitric oxide (NO) formation, and cyclic guanosine monophosphate (cGMP).

Methods-Urinary nitrate was determined by gas chromatography, cGMP by radioimmunoassay.

Results-A significant $(\mathrm{p}<0.001)$, more than three fold increase of urinary nitrate excretion was found in rats 20 days after induction of adjuvant arthritis compared with non-arthritic rats. There was no significant difference in urinary cGMP excretion between arthritic rats and control animals.

Conclusion-The data suggest that the dramatic increase of urinary nitrate excretion is due to increase of NO synthesis by the inducible form of NO synthase.
\end{abstract}

(Ann Rheum Dis 1994; 53: 547-549)

Nitric oxide (NO) has been shown to be a major messenger molecule with many physiological and pathophysiological functions. ${ }^{1} \mathrm{NO}$ is synthesised from L-arginine by the NO synthase. Two major types of this enzyme have been identified: 1) The constitutive NO synthase is responsible for regulation of vascular tone, platelet aggregation and neuronal signal transduction; these actions are mediated by activation of soluble guanylate cyclase followed by increased concentrations of cyclic guanosine monophosphate (cGMP); ${ }^{1} 2$ ) The inducible NO synthase; after induction by endotoxin and certain cytokines, this isoform produces large quantities of $\mathrm{NO}$ in contrast to small amounts of $\mathrm{NO}$ by the constitutive form. The NO production by the inducible NO synthase contributes to the cytotoxic properties of macrophages, ${ }^{2}$ monocytes ${ }^{3}$ and neutrophils. ${ }^{4}$ Although it is obvious that NO acts as part of the cell-mediated immune response, the precise role of this mediator molecule in inflammation is not clear; anti-inflammatory properties have also been described. ${ }^{5}$

Little is known about the in vivo synthesis of $\mathrm{NO}$ in inflammatory joint diseases. Farrell et al reported elevated levels of nitrite in joint fluid and serum of patients with rheumatoid arthritis. We have therefore studied the excretion of the major urinary metabolite of NO, nitrate, in rats with adjuvant arthritis, a well established model of polyarthritis. For this we applied a recently developed, highly spec ific and sensitive gas chromatographic method for determination of nitrite and nitrate in serum, urine, synovia and cell supernatants. NO itself is difficult to measure directly, because of its very short half life in biological fluids. NO is readily oxidised to nitrite and nitrate, ${ }^{7}$ which are excreted rapidly into urine. It has been shown, that the major source of urinary nitrate, in the absence of excess nitrate intake in food, is endogenously synthesised NO. ${ }^{8}$ Therefore the NO synthase activity can be assessed reliably by measuring urinary nitrate excretion, as reported by Suzuki et al ${ }^{9}$ and our group (Bode-Böger et al).

\section{Materials and methods}

ANIMALS AND ARTHRITIS INDUCTION

Twelve male Sprague Dawley rats with adjuvant arthritis and 12 non-arthritic rats of the same strain and age were purchased from Charles River, Cleon, France. Adjuvant arthritis was induced as described by Gouret et al. ${ }^{10}$ As a control group 12 non-arthritic rats of the same strain were held under the same conditions. Both groups received unlimited amounts of tap water (nitrate concentration $<1.6 \mu \mathrm{mol} /$ 1 , nitrite concentration $<0 \cdot 1 \mu \mathrm{mol} / \mathrm{l}$ ) and food (RM-204, Eggersmann, Rinteln, Germany).

EXPERIMENTAL PROTOCOL

At day 20 after arthritis induction secondary arthritic lesions at all four paws, penis and tip of the nose of each rat were examined according to the following score (maximal value/animal $=16): 0=$ No erythema and no inflammation; $1=$ Distinct to moderate erythema of 1 paw or swelling of 1 joint at one paw; $2=$ Swelling of $2-3$ joints at one paw or swelling of penis or tip of the nose; $3=$ Swelling of 4-5 joints at one paw or extensive erythema and swelling of one paw.

Twenty four hour urine samples were collected in metabolism cages at day 20 after inoculation; at the same day the body weight of each rat was assessed. Bacterial growth in the urine was prevented by addition of $2 \mathrm{ml}$ 2 -propanol into the collection tube.

ANALYSES

Urinary nitrate was determined by a gas chromatographic method, based on a reaction 
of nitrate with trimethoxybenzene to form trimethoxynitrobenzene. Fifty $\mu \mathrm{l}$ aliquots of urine were diluted with $50 \mu$ l double-distilled water and treated with $300 \mu$ l silver sulphate solution $(100 \mathrm{mg} / \mathrm{ml})$ for chloride precipitation. After centrifugation $(5 \mathrm{~min}, 8000 \times \mathrm{g}$ ) $300 \mu \mathrm{l}$ aliquots of the supernatant were mixed with $300 \mu$ l of concentrated sulphuric acid, $20 \mu l$ trimethoxybenzene in acetone $(1 \mathrm{mg} / \mathrm{ml})$ and $10 \mu \mathrm{l}$ dimethoxynitrobenzene in acetone $(250 \mathrm{ng} / \mu \mathrm{l})$ as internal standard. After incubation $\left(10\right.$ minutes at $\left.60^{\circ} \mathrm{C}\right)$ the generated nitroaromates were extracted with $800 \mu l$ of toluene. The toluene layer was drawn off and shaken with $2 \mathrm{ml}$ of a $4 \mathrm{M}$ aqueous sodium hydroxide solution. Subsequently $100 \mu$ l of the toluene phase were diluted with $900 \mu \mathrm{l}$ of toluene for gas chromatographic analysis. Gas chromatography was performed on a Carlo Erba HRGC5160 (Fisons Instruments, Mainz, Germany) equipped with an A200S autosampler and an ECD HT40 electron capture detector. An OV1701 fused silica capillary column (Machery and Nagel, Düren, Germany) was used for chromatographic separation. Helium $(75 \mathrm{kPa})$ was applied as carrier gas and nitrogen $(150 \mathrm{kPa})$ as make up gas. Oven temperature was held at $150^{\circ} \mathrm{C}$ for two minutes then programmed to $280^{\circ} \mathrm{C}$ at a rate of $40^{\circ} \mathrm{C} /$ minutes and held at $280^{\circ} \mathrm{C}$ for two minutes. The intra- and interassay coefficients of variation were below $3.5 \%$. The detection limit of the method was $5 \cdot 2 \mathrm{nmol}$ nitrate $/ \mathrm{ml}$. The method was validated by a recently published gas chromatography/tandem mass spectrometry assay ${ }^{11}$ and showed a coefficient of correlation of $r=0.91, n=15$, in the range of urinary nitrate levels.

For the determination of cGMP levels in urine we used a radioimmunoassay method as described previously. ${ }^{12}$

Urinary creatinine was determined spectrophotometrically using the alkaline picric acid method in an automatic analyser (Beckman, Galway, Ireland). The urinary excretion rates of nitrate and cGMP were corrected by creatinine excretion.

\section{STATISTICS}

Data are expressed as mean (SD). Statistical significance of differences was determined by an unpaired $t$ test. A p-value $<0.05$ was considered significant.

\section{Results}

The mean (SD) arthritis score was 10 (1) in arthritic animals at day 20 after induction of adjuvant arthritis. In the non-arthritic rats no signs of inflammation could be examined, therefore the arthritis score of each rat was 0 . The body weight was significantly $(p<0.001)$ lower in arthritic rats than in healthy control animals [218 (5) g versus 242 (4) g].

The urinary nitrate excretion was significantly increased in rats suffering from arthritis compared with the non-arthritic control group (figure). Urinary cGMP excretion was slightly, but not significantly lower in arthritic

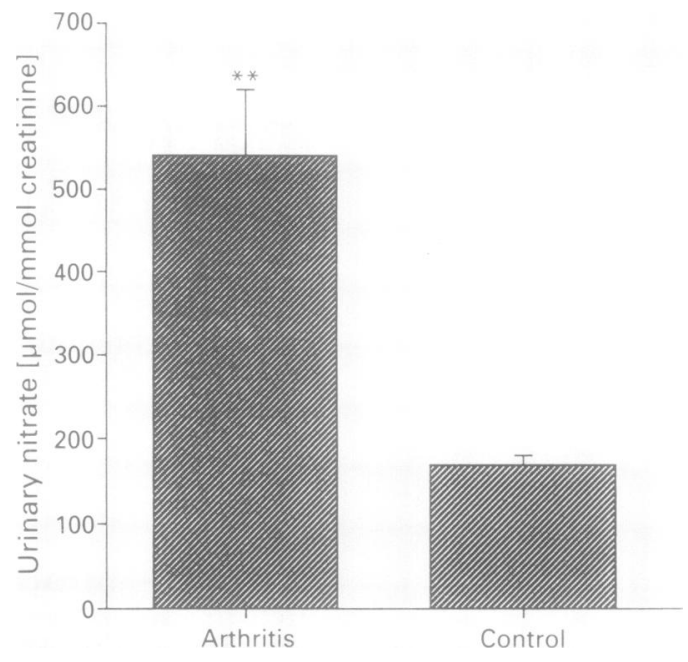

Urinary nitrate excretion in arthritic and non-arthritic control rats. Mean (SE), $n=12$.

${ }^{\star \star} p<0.001$ versus controls in two-tailed, unpaired $\mathrm{t}$ test.

rats $[510(44) \mathrm{nmol} / \mathrm{mmol}$ creatinine] than in controls [747 (33) $\mathrm{nmol} / \mathrm{mmol}$ creatinine]. There was no difference in urinary creatinine excretion between arthritic [72 (5) $\mu \mathrm{mol} / \mathrm{d}]$ and non-arthritic rats $[68(3) \mu \mathrm{mol} / \mathrm{d}]$.

\section{Discussion}

In the present study we have demonstrated that the urinary nitrate excretion was increased more than three fold in rats suffering from adjuvant arthritis compared with healthy controls. There was no higher food intake in arthritic rats, resulting in higher body weight, which could account for this result; on the contrary, the arthritic animals had lower body weights than the non-arthritic rats. The drinking water did not measurably contribute to urinary nitrate excretion. Therefore higher urinary nitrate excretion due to excess food and water intake can be ruled out and the elevated urinary nitrate excretion of arthritic rats suggests elevated NO synthesis.

Ialenti $e t a l^{13}$ demonstrated elevated nitrite generation by peritoneal macrophages collected from rats with adjuvant arthritis compared with controls; nitrite generation and the severity of arthritis was exacerbated by L-arginine, the source for NO production, and supressed by $\mathrm{N}^{\mathrm{G}}$-nitro-L-arginine methyl ester, an inhibitor of $\mathrm{NO}$ synthesis.

In rats with arthritis, induced by injection of streptococcal cell wall fragments, McCartneyFrancis et $a l^{14}$ found elevated NO production by synovial tissue of inflamed joints and by polymorphonuclear cells. Administration of $\mathrm{N}^{\mathrm{G}}$-monomethyl-L-arginine profoundly reduced NO production by synovial tissue, synovial inflammation and tissue damage. In our study urinary cGMP excretion was not increased in rats with adjuvant arthritis in spite of a more than three fold increase in urinary nitrate excretion. This points to an activation of the inducible form of the NO synthase, because urinary nitrate and cGMP excretion are influenced in parallel when the constitutive NO synthase is activated, as reported by Kanno et al. ${ }^{15}$ 
In summary, endogenous NO formation by the inducible NO synthase is enhanced in adjuvant arthritis. The determination of urinary nitrate excretion enables repeated and non-invasive assessment of endogenous NO formation under defined conditions. Further investigations in animal models of arthritis and in clinical studies are needed to study whether inhibition of NO synthesis is a new therapeutic approach in the treatment of inflammatory joint diseases.

We are grateful to Mrs A Otten and $\mathrm{Mr} \mathrm{H}$ Steinberger for their excellent technical assistance.

Moncada S, Higgs A. The L-arginine-nitric oxide pathway NEngl F Med 1993; 329: 2002-12.

2 Hibbs J B jr, Taintor R R, Vavrin Z, Rachlin E M. Nitric oxide: a cytotoxic activated macrophage effector molecule. Biochem Biophys Res Commun 1988; 157: $87-94$

3 Hunt N C A, Goldin R D. Nitric oxide production by monocytes in alcoholic liver disease. $\mathcal{F}$ Hepatol 1992; 14:

4 Moncada S. The L-arginine: nitric oxide pathway. Acta Physiol Scand 1992; 145: 201-27.

5 Billiar T R, Curran R D, Harbrecht B G, Stuehr D J, Demetris A J, Simmons R L. Modulation of nitrogen oxide synthesis in vivo: $\mathrm{N}^{\mathrm{G}}$-monomethyl-L-arginine inhibits endotoxin-induced nitrite/nitrate biosynthesis while promoting hepatic damage. f Leukoc Biol 1990; 48: $565-9$.
6 Farrell A J, Blake D R, Palmer R M J, Moncada S. Increased concentrations of nitrite in synovial fluid and serum samples suggest increased nitric oxide synthesis in rheumatic diseases. Aum Rheum Dis 1992; 51: 1219-22.

7 Wennmalm A, Benthin G, Peterson A-S. Dependence of the metabolism of nitric oxide (NO) in healthy human whole blood on the oxygenation of its red cell hemoglobin. $\mathrm{Br}$ blood on the oxygenation of its

F Pharmacol 1992; 106: 507-8.
8 Granger D L, Hibbs J B jr, Broadnax L M. Urinary nitrate excretion in relation to murine macrophage activation. f Immunol 1991; 146: 1294-302.

9 Suzuki H, Ikenaga H, Hishikawa K, Nakaki T, Kato R, Saruta $\mathrm{T}$. Increases in $\mathrm{NO}_{2} \mathrm{NO}_{3}$ excretion in the urine as an indicator of endothelium-derived relaxing factor during elevation of blood pressure. Clin Sci 1992; 82 631-4.

10 Gouret C, Mocquet G, Raynaud G. Use of freund's adjuvant arthritis test in anti-inflammatory drug screening in the rat: value of animal selection and preparation at the in the rat: value of animal selection and preparation
breeding center. Lab Anim Sci 1976; 26: 281-7.

11 Gutzki F-M, Tsikas D, Alheid U, Frölich J C. Determination of endothelium derived nitrite/nitrate by gas chromatography/tandem mass spectrometry using $\left({ }^{15} \mathrm{~N}\right) \mathrm{NaNO}_{2}$ as internal standard. Biol Mass Spectrom 1992; 21: 97-102.

12 Kuhn M, Otten A, Frölich J C, Förstermann U. Endothelia cyclic GMP and cyclic AMP do not regulate the release of endothelium-derived relaxing factor/nitric oxide from bovine aortic endothelial cells. $\mathcal{F}$ Pham Exp Ther 1991; 256: $677-82$.

13 Ialenti A, Moncada S, Di Rosa M. Modulation of adjuvant arthritis by endogenous nitric oxide. $\mathcal{F}$ Pharmacol 1993 ; 110: 701-6.

14 McCartney-Francis N, Allen J B, Mizel D E, et al, Suppression of arthritis by an inhibitor of nitric oxide synthase. F Exp Med 1993; 178: 749-54.

15 Kanno K, Hirata Y, Emori T, Ohta K, Eguchi S, Imai T, Marumo F. L-arginine infusion induces hypotension and diuresis/natriuresis with concomitant increased urinary excretion of nitrite/nitrate and cyclic GMP in humans. Clin Exp Pharmacol Physiol 1992; 19: 619-25. 